\title{
Determinantes da Demanda Brasileira por Importação de Arroz do Mercosul
}

\author{
Daniel Henrique Dario Capitani ${ }^{1}$ \\ Sílvia Helena Galvão de Miranda ${ }^{2}$ \\ João Gomes Martines Filho ${ }^{3}$
}

Resumo: Desde meados da década de 1990, o arroz é um dos principais produtos agrícolas importados pelo Brasil, principalmente do Uruguai e da Argentina, o que frequentemente gera questionamentos dos orizicultores brasileiros. $\mathrm{O}$ objetivo deste artigo é analisar os determinantes das importações brasileiras deste cereal, e para tanto, apresenta-se um modelo econômico visando analisar esta relação comercial no Mercosul, assumindo que as importações brasileiras de arroz são resultantes de um excesso de demanda doméstica pelo cereal. Utiliza-se um Modelo Autorregressivo Vetorial - VAR estrutural. Os resultados mostram uma forte relação do volume importado com o preço doméstico do arroz e com a taxa de câmbio. Verifica-se uma significativa participação do preço de importação na explicação do preço doméstico. A quantidade importada de arroz responde positivamente a um choque positivo no preço doméstico e negativamente a choques positivos no preço de importação e na taxa de câmbio. Verifica-se uma relação de bicausalidade entre o preço doméstico e o preço de importação de arroz. Uma das principais conclusões é que a demanda por importação reage imediatamente a choques no preço doméstico e taxa de câmbio, e posteriormente, a choques no preço de importação, sugerindo dificuldades em substituir imediatamente o volume importado no mercado doméstico.

Palavras-chave: Arroz, demanda, importação, Mercosul, VAR.

1 Doutorando em Economia Aplicada - Esalq/USP. E-mail: danielcapitani@yahoo.com.br

2 Professora do Departamento de Economia, Administração e Sociologia - Esalq/USP. E-mail: smiranda@esalq.usp.br

3 Professor do Departamento de Economia, Administração e Sociologia - Esalq/USP. E-mail: martines@usp.br 


\begin{abstract}
Since the middle of the 90's, rice has been one of the main agricultural products imported by Brazil, particularly from Uruguay and Argentina, which very often raises concerns to Brazilian rice producers. This paper aims to analyze the factors that determine the Brazilian rice imports, and therefore proposes an economic model to examine these trade flows in Mercosur, assuming that the Brazilian rice imports results from a domestic demand surplus. An econometric model Vector Auto-regressive (structural VAR) is applied. Results show a strong relationship among rice imports and domestic rice prices, as well as the exchange rate. A significant effect of import prices over domestic prices has been verified. The quantity of rice imports relates positively to an increase of domestic prices and negatively to an increase of import prices, as well as increases in the exchange rate. A bicausality relationship is verified between domestic and import prices for rice. One of the major conclusions is that Brazilian rice imports answer immediately to changes in domestic prices and exchange rate and react one quarter later to changes in import prices suggesting a delay over rice importers to substitute imports by the domestic rice.
\end{abstract}

Key-words: Rice, demand, imports, Mercosur, VAR.

Classificação JEL: C32, F15, Q11, Q17.

\title{
1. Introdução
}

Um dos alimentos mais importantes na nutrição humana, sobretudo nos países asiáticos e nas regiões de baixa renda, como em países da África e América Latina, o arroz desempenha papel estratégico sob os aspectos econômico e social.

Os países asiáticos são os grandes produtores e consumidores do cereal, com China e Índia representando aproximadamente $50 \%$ do total produzido e consumido no mundo. O Brasil é o país não asiático de maior produção e consumo de arroz, porém, sua participação no mercado mundial é inferior a $2 \%$, tanto na produção, quanto no consumo do cereal (FOOD AND AGRICULTURAL ORGANIZATION - FAO, 2008). De acordo com dados da Companhia Nacional de Abastecimento (CONAB, 2008), o país produziu pouco mais de 12 milhões de toneladas, e consumiu aproximadamente 13 milhões de toneladas de arroz na safra 2007/08, indicando um déficit na relação produção/consumo.

Ao contrário da realidade atual, até a década de 1980, a produção desta commodity no país era suficiente para atender sua demanda interna. Entretanto, as mudanças no padrão de consumo no país, como o aumento da demanda pelo arroz longo-fino, atreladas à abertura comercial e à integração econômica do país com o exterior já no início da década de 1990, principalmente pela sua 
inserção no Mercado Comum do Sul (Mercosul), levaram o país a uma condição de importador líquido do cereal.

Além disso, outros fatores também influenciaram a entrada de arroz estrangeiro no Brasil a partir deste período, entre os quais: a redução de tarifas alfandegárias para países membros do Mercosul; a manutenção do Real valorizado perante o dólar a partir de julho de 1994 até janeiro de 1999, facilitando a importação de bens; as elevadas taxas de juros básicas da economia, o que dificultou o acesso ao crédito, e ocasionou uma maior propensão ao endividamento dos produtores internos (BARATA, 2005), perdendo competitividade em seu custo de capital; e o agravamento da restrição fiscal na década de 1990, afetando as políticas governamentais de garantia de preços mínimos e compra de excedentes de produção, com o apoio à formação de estoques pela iniciativa privada (ADAMI, 2005).

O advento do Mercosul, em 1995, foi um elemento decisivo na definição do padrão comercial que se estabelecia a partir da década de 1990 no Brasil. Alguns setores tradicionalmente protegidos em cada um dos países membros do Mercosul começaram a ter concorrência de produtos similares ou substitutos produzidos pelos novos parceiros, enquanto aqueles que não possuíam vantagem competitiva tiveram sua participação reduzida na economia de seus respectivos países. Este foi o caso de alguns setores na agricultura brasileira, entre eles: trigo, arroz, derivados lácteos, alho, batata, cebola, carne bovina e frutas de clima temperado (OSAKI, 2003).

Ao longo das últimas duas décadas, o Brasil vem enfrentando forte concorrência do Uruguai e Argentina no abastecimento de seu mercado interno, o que, frequentemente gera questionamentos do setor orizícola da região Sul do País junto ao governo sobre a abertura comercial neste setor. Segundo Ferreira et al. (2005), entretanto, os impactos dessa concorrência só não foram maiores para a orizicultura brasileira em decorrência: do aumento no consumo mundial de alimentos e no consumo interno de arroz; da elevação nos preços das commodities mundiais; das novas tecnologias de produção e do surgimento de novas variedades de arroz irrigado no mesmo período; da intervenção moderada do governo; do início do profissionalismo no setor e da desvalorização cambial nos últimos anos.

A evolução da produção de arroz no mercado uruguaio é notável entre 1989 e 2008, passando de 365 mil para 1,2 milhão de toneladas e com a característica de estar voltada para a exportação, tendo o Brasil como principal mercado de destino, chegando a representar quase $85 \%$ das exportações uruguaias em 2003 (ACA, 2008). Além disso, o Uruguai tem trabalhado na diversificação e qualidade de seu arroz e na abertura de novos mercados, sobretudo no Oriente Médio.

A competitividade uruguaia no comércio internacional de arroz se deve às articulações institucionais entre produtores, indústrias beneficiadoras e distribuidoras do cereal, além do governo local. Estes agentes se interligam 
desde a venda do cereal produzido pelos produtores aos moinhos, via contratos negociados com preços institucionalizados ${ }^{4}$, passando pela participação dos produtores nas indústrias beneficiadoras até a integração vertical das empresas agroindustriais, que têm sob seu poder algumas etapas da produção, beneficiamento e comercialização do cereal.

Já o setor orizícola argentino, segundo Pagliettini et al. (1999), apresentava, até a década de 1980, baixo nível de comércio com outros países, além do pequeno consumo interno, da baixa qualidade das variedades cultivadas e do elevado custo de produção interno, que desestimulavam o aumento de área cultivada no país.

A reestruturação do setor a partir de 1990 ocorreu em virtude de um novo arranjo entre alguns grandes grupos industriais e investimentos em tecnologia, em que ocorreu um aumento no tamanho das propriedades e redução no número de produtores, resultando em maior concentração na indústria beneficiadora, cujo objetivo visava basicamente à entrada no mercado brasileiro de arroz. A produção argentina passou de 400 mil toneladas no início da década de 1990 para cerca de 1,2 milhão de toneladas em 2008 (ARGENTINA, 2008). A ligação é bastante forte com o mercado brasileiro, tanto que houve uma forte retração nos seus volumes exportados a partir da desvalorização cambial brasileira em 1999, com reflexos diretos sobre sua produção interna.

A motivação deste artigo se dá, primeiramente, em razão do reduzido número de trabalhos com foco econômico que abordem o setor orizícola brasileiro e, sobretudo, que descrevam e modelem o padrão e os determinantes da importação brasileira deste cereal, em que o Mercosul tem representatividade tão significativa. Em segundo lugar, este artigo visa contribuir e agregar maior conteúdo às discussões existentes entre produtores e governo ao longo dos últimos anos, em relação às possíveis distorções no mercado doméstico, decorrentes da entrada de arroz proveniente do Mercosul.

Desta forma, este artigo aborda as transformações do mercado brasileiro de arroz, desde a abertura econômica no início da década de 1990 até o presente, dando ênfase ao processo de criação do Mercosul a partir de 1995. Isto permite visualizar, mesmo que indiretamente, parte dos efeitos da integração no Mercosul, a partir da construção de um modelo econômico que represente a importação brasileira de arroz e sua dinâmica.

O objetivo geral do presente artigo é de identificar os determinantes da demanda de arroz importado pelo Brasil, através da análise das variáveis

4 Os preços institucionalizados são fixados e negociados a partir do preço ao produtor, por representantes de todos os elos da cadeia, que levam em consideração seus próprios preços e custos. É denominado como preço convênio, fixado uma vez ao ano, com vigência para a safra corrente, correspondendo ao valor que será pago pelos moinhos aos produtores no final da safra (SCARLATO, 2003). 
que determinam os fluxos da importação brasileira do arroz proveniente da Argentina e do Uruguai.

Esta análise é conduzida utilizando um Modelo de Vetores Autorregressivos (VAR), que permite melhor estruturação das relações entre as variáveis analisadas ao longo do período em questão, e sob a ótica de um modelo teórico que considera as importações como um excedente da demanda doméstica.

Este trabalho é fundamentado na hipótese de que a abertura comercial, seguida da formação do Mercosul, foi um elemento decisivo para explicar o padrão da importação brasileira de arroz em período recente.

\section{Revisão bibliográfica}

Com o objetivo de analisar os fatores que influenciam o crescimento das importações brasileiras de arroz, inclusive buscando avaliar a importância da abertura econômica - especialmente da criação do Mercosul -, este trabalho revisou alguns estudos que abordaram determinantes de demanda por importação, bem como os modelos econômicos apresentados na literatura para a especificação dessa função.

O estudo de funções de importação e exportação para averiguar fatos referentes ao comportamento do comércio entre os países é uma contribuição para pesquisas que buscam compreender os efeitos de alterações das políticas macroeconômicas e comerciais das nações sobre o comércio entre elas.

$\mathrm{Na}$ literatura, há trabalhos bem fundamentados que buscaram teorizar sobre as especificações das equações de comércio internacional, entre eles: Houthakker e Magee (1969), Leamer e Stern (1970), Dib (1987), Zini Jr. (1988), Portugal (1992), Resende (1997), Castro e Cavalcanti (1997), Carvalho e Parente (1999), Carvalho e Negri (2000), Resende (2001), Osaki (2003) e Santos (2004).

Alguns trabalhos também foram dedicados a estruturar modelos que relacionassem os fluxos de comércio externo com a oferta e demanda domésticas, como o próprio trabalho de Santos (2004), para importação (modelo de compras externas, como um excedente de demanda) e os de Miranda (2001) e Barros et al. (2002), para fluxos de exportação (modelo de vendas externas, como excedentes de oferta).

Partindo-se do ferramental teórico citado, este estudo estrutura um modelo de compras externas para a determinação de um modelo empírico que auxilie na compreensão dos determinantes das importações brasileiras de arroz do Mercosul. Neste caso, parte-se do pressuposto básico da teoria econômica de que um excesso de demanda doméstica leva a um aumento nas importações de um país, desde que não haja proibição ou restrições às mesmas.

Adaptando-se essa modelagem ao foco deste trabalho, analisam-se os determinantes das quantidades importadas de arroz em casca, partindo da 
relação oferta e demanda domésticas. Este mercado pode ser representado matematicamente pelo seguinte modelo estrutural:

$$
M^{d}=Q^{s}-Q^{d}
$$

em que $M^{d}$ se refere à quantidade a ser importada, resultante do excesso de demanda interna; $Q^{d}$ corresponde à quantidade demandada de arroz internamente e $Q^{s}$ é a quantidade de arroz ofertada no mercado interno.

Assume-se que a representação destes dois componentes está como função de:

$$
Q^{s}\left(P_{d}, W\right)
$$

$$
Q^{d}\left(P_{d}, P_{m}, E, Y_{n}, Z\right)
$$

em que $P_{d}=$ Preço do arroz no mercado doméstico (em R\$); $P_{m}=$ Preço do arroz importado (em US\$); $Y_{n}=$ Renda nominal doméstica; $E=$ Taxa de câmbio nominal (R\$/US\$); Z = Variáveis deslocadoras da demanda (por exemplo, preço do produto substituto, mudanças nas preferências dos consumidores); e $W=$ Variáveis deslocadoras da oferta (safra, melhoramento genético, tendência, estoques, disponibilidade de crédito).

Portanto, substituindo-se (2) e (3) na expressão (1), tem-se as compras externas, representadas pela seguinte equação:

$$
M^{d}=Q^{s}\left(P_{d}, W\right)-Q^{d}\left(P_{d}, P_{m}, E, Y_{n}, Z\right)
$$

\subsection{Modelo empírico}

Objetivando-se compreender os determinantes das importações de arroz argentino e uruguaio pelo Brasil, estimam-se as funções de demanda brasileira deste produto proveniente do Mercosul, considerando-se a mesma como uma única região. Assim, assume-se que as importações provenientes da Argentina e Uruguai representam as importações totais oriundas do Mercosul, dada a pequena importância do Paraguai neste mercado, no período analisado.

Com base nos estudos já realizados pelos autores citados na revisão bibliográfica e no conhecimento do funcionamento do mercado de arroz, também apoiado na literatura especializada, a especificação adotada para estimar as quantidades importadas utiliza como variáveis explicativas a renda real brasileira, o preço doméstico de arroz, o preço pago pelas importações do cereal do Mercosul e a taxa de câmbio.

Uma das variáveis comumente utilizadas na literatura e não considerada neste trabalho é o preço de produtos substitutos. Neste caso, o preço de substitutos do arroz no mercado doméstico seria o preço do arroz nos mercados 
da Argentina e Uruguai, os quais não possuem séries disponíveis para o mesmo período de análise, entre 1989 e 2008. Por outro lado, o presente artigo inclui como variável um valor médio de importação consolidado para o Mercosul, conforme descrito no tópico 2.3. A restrição de trabalhar com valores médios de importação, devido à falta de dados sobre os preços médios de importação, também é levantada por Leamer e Stern (1970) e Santos (2004).

Desta forma, a equação (4), que representa as compras externas, pode ser expressa da seguinte maneira:

$$
\begin{aligned}
& M^{d}=\left(\alpha_{0}+\alpha_{1} P_{d}+\alpha_{2} W\right)-\left(\beta_{0}+\beta_{1} P_{d}+\beta_{2} P_{m}+\beta_{3} E+\beta_{4} Y_{n}+\beta_{5} Z\right)+\varepsilon \\
& M^{d}=\left(\alpha_{0}-\beta_{0}\right)+\left(\alpha_{1}-\beta_{1}\right) P_{d}+\alpha_{2} W-\beta_{2} P_{m}-\beta_{3} E-\beta_{4} Y_{n}+\beta_{5} Z+\varepsilon
\end{aligned}
$$

em que $\alpha_{0}, \alpha_{1}, \alpha_{2}, \beta_{0}, \beta_{1}, \beta_{2}, \beta_{3}, \beta_{4}, \beta_{5}$ são coeficientes associados às variáveis explicativas do modelo e $\varepsilon$ é o termo de erro.

Como forma de adequar o modelo proposto na equação (6), com os objetivos de identificar se houve impactos na importação de arroz em decorrência da abertura econômica, da criação do Mercosul, do plano de estabilização monetária (Plano Real) e da mudança do regime cambial, com drástica desvalorização do Real em 1999, são adicionadas variáveis dummies (binárias), resultando em:

$$
\begin{aligned}
& M^{d}=\left(\alpha_{0}-\beta_{0}\right)+\left(\alpha_{1}-\beta_{1}\right) P_{d}+\alpha_{2} W-\beta_{2} P_{m}-\beta_{3} E-\beta_{4} Y_{n}-\beta_{5} Z+ \\
& \gamma_{1} D_{1}+\gamma_{2} D_{2}+\gamma_{3} D_{3}+\gamma_{4} D_{4}+\varepsilon_{t}
\end{aligned}
$$

em que $D_{1}=$ dummy referente à abertura econômica a partir de março de 1990; $D_{2}=$ dummy referente à implantação do Plano Real em julho de $1994 ; D_{3}=$ dummy referente à criação do Mercosul a partir de janeiro de $1995 ; D_{4}=$ dummy referente à desvalorização do Real a partir de janeiro de 1999; $Y_{1} Y_{2} Y_{3} Y_{4}=$ coeficientes associados às variáveis dummies; e $\varepsilon_{t}=$ erro aleatório no período de análise ${ }^{5}$.

\subsection{Procedimentos metodológicos}

O modelo econômico apresentado anteriormente tem suas hipóteses testadas através da metodologia de Vetores Autorregressivos (VAR). Os modelos VAR consistem em sistemas de equações simultâneas que procuram captar a existência de relações de interdependência entre as variáveis, permitindo avaliar o impacto de choques aleatórios sobre uma dessas variáveis, especificamente.

5 Conforme abordado posteriormente, na fonte de dados, o período de análise das variáveis aqui representadas vai de janeiro de 1989 a setembro de 2008, desde o início da série disponível em Brasil (2008b), e permitindo abordar um período anterior à abertura econômica brasileira até o presente momento. 
A principal característica de um modelo VAR é a forma como relaciona as variáveis de forma simétrica, o que implica que não importa mais a direção de dependência entre elas, com todas as variáveis tendo a mesma importância no modelo, extinguindo a identificação de variável dependente ou independente.

A vantagem de um VAR é a exigência de um grau reduzido de restrições teóricas sobre sua estrutura. Exige-se apenas a especificação de um conjunto de variáveis que interajam dentro do sistema e a determinação do número de defasagens necessárias para captar a dinâmica de interação entre as variáveis do modelo.

Antes de escolher o VAR para a estimação do modelo, foi realizada uma revisão de outras abordagens utilizadas na literatura, inclusive do modelo de equações simultâneas. Contudo, o VAR foi preferido pelas suas vantagens em permitir estimar as relações contemporâneas realmente relevantes para o modelo, em utilizar a função impulso-resposta, permitindo obter as relações causais entre as variáveis estudadas, sem a necessidade de aplicar um teste de causalidade adicional.

Segundo Alves (2002), entre os objetivos da utilização deste modelo está a obtenção do tempo de reação e da intensidade das respostas a choques sobre as variáveis, bem como da direção, padrão e duração dessas respostas. Esta é uma contribuição que o uso da metodologia VAR provê em comparação a outras metodologias registradas na literatura.

De acordo com Enders (2004), o uso da metodologia VAR permite a obtenção das elasticidades impulso para $k$ períodos posteriores, que possibilitam avaliar o comportamento das variáveis em resposta a choques individuais sobre quaisquer dos componentes do sistema.

Esta metodologia possibilita ainda a decomposição histórica da variância dos erros de previsão, $k$ períodos à frente, em percentagens a serem distribuídas a cada variável do componente do sistema.

Contudo, segundo Hamilton (1994, apud Alves, 2006), a metodologia VAR é limitada ao fato de possuir uma estrutura recursiva para as relações contemporâneas entre suas variáveis. $\mathrm{O}$ autor ressalta, porém, que esta limitação é superada através do modelo VAR estrutural, desenvolvido por Sims (1986) e Bernanke (1986), que permite o estabelecimento de relações contemporâneas, tomando a teoria econômica como referência.

A identificação do modelo VAR estrutural, segundo Enders (2004), é definida através da imposição de $\left(n^{2}-n\right) / 2$ restrições, que indicará o máximo de relações contemporâneas permitidas a inserir na matriz $\mathbf{B}_{0}$.

Assim, um modelo teórico estabelecido e que indique as restrições a serem impostas às relações contemporâneas entre as variáveis deve ser utilizado, a fim de se obter identificação no modelo empírico.

O modelo VAR estrutural é representado por:

$$
B_{0 x t}=B_{1} x_{t-1}+B_{2} x_{t-2}+\ldots+B_{p} x_{t-p}+e_{t}
$$


em que $\boldsymbol{x}_{t}$ é um vetor com variáveis de interesse; $\boldsymbol{B}_{j}$ são matrizes $(n \times n)$ para qualquer $j$, com $\boldsymbol{B}_{0}$ sendo a matriz de relações contemporâneas; $x_{t}$ é um vetor com variáveis de interesse e; $e_{t}$ é um vetor $n \times 1$ de choques ortogonais, no qual seus componentes são não correlacionados serialmente, e adota-se a suposição de que eles não têm causa comum, sendo tratados como mutuamente não correlacionados, de tal forma que $\mathrm{E}\left(\boldsymbol{e}_{t} \boldsymbol{e}_{t}{ }^{\prime}\right)=\mathrm{D}$. A equação (8) também pode ser descrita como:

$$
B(L) x_{t}=e_{t}
$$

onde $\mathrm{B}(\mathrm{L})$ é um polinômio em $L$, com $L$ sendo o operador de defasagem, tal que $L_{j} x_{t}=x_{t-j}$, para $j$ inteiro.

A forma reduzida da equação (9) é obtida a partir de sua pré-multiplicação por $\boldsymbol{B}_{0}^{-1}$, que resulta em:

$$
A(L) x_{t}=u_{t}
$$

em que $A(L)=B_{0}^{-1} B(L), A_{0}=I_{n}$ e $u_{t}=B_{0}^{-1} e_{t}$.

Disso, estima-se a equação (10) pelo Método de Mínimos Quadrados Ordinários. Utilizando-se do procedimento de Bernanke (1986), podem-se estimar os coeficientes de $\mathbf{B}_{0}$ e $\mathbf{D}$, a partir da maximização do logaritmo da função de verossimilhança.

Se o processo é estacionário, a equação (10) pode ser escrita na forma de média móvel (LÜTKEPOL, 1991, apud ALVES, 2006):

$$
x_{t}=C(L) u_{t}
$$

em que $C(L)$ é um polinômio de ordem infinita de matrizes $\mathbf{C}_{\mathbf{j}}$. Reescrevendo-se a equação (11), em termos de $\mathbf{e}_{\mathbf{t}}$, tem-se:

$$
x_{t}=C(L) B_{0}^{-1} e_{t}
$$

Pode-se, através de um modelo VAR, a partir da equação (12), analisar os efeitos de choques e a importância de cada variável para a explicação da variância dos erros das demais (ALVES, 2006). Estes dois procedimentos utilizados são conhecidos como função impulso-resposta e decomposição da variância do erro de previsão.

Segundo Enders (2004), quando um estudo busca obter funções impulso-resposta e a decomposição da variância, é preciso utilizar-se de choques estruturais e, consequentemente, impor restrições sobre a matriz de relações contemporâneas de modo a tornar o sistema identificado.

Assim como apresentado nas equações anteriores, Enders (2004) descreve que a função impulso-resposta do modelo VAR é escrita a partir da representação média-móvel, em que suas variáveis são expressas em termos dos valores correntes e passados de seus erros, permitindo que seja traçado o caminho de vários choques sobre as variáveis do sistema. 
De acordo com Margarido et al. (2004), a decomposição da variância dos erros de previsão mostra a evolução do comportamento dinâmico apresentado pelas variáveis de um sistema econômico ao longo do tempo, ou seja, possibilita separar a variância dos erros de previsão para cada variável em componentes que podem ser atribuídos por ela própria e pelas demais variáveis, isoladamente.

Assim, segundo Ishii (2008), é possível conhecer a proporção dos movimentos em uma série $x_{t}$ devido ao choque na própria variável, ou ao choque nas outras variáveis. Este procedimento também possibilita afirmar que, se o choque nas outras variáveis não explicar em nada a variância do erro de previsão para a sequência da série $x_{t}$, diz-se que a sequência $x_{t}$ é exógena, ou que evolui independentemente dos choques nas outras variáveis.

Para determinação do número de defasagens (ordem do processo autorregressivo) a ser adotado nos testes de raiz unitária, foram utilizados os critérios de Akaike (AIC) e Schwarz (SBC), assim como para a determinação do número de defasagens no teste de cointegração, para uma versão multiequacional.

Diversos estudos adotam procedimentos para verificar a ordem de integração de uma série temporal. Entre os procedimentos, o de Dickey e Fuller (1981) tem sido bastante utilizado. O presente estudo também utilizou o procedimento de Dickey e Fuller (1981) para verificar a ordem de integração das séries temporais utilizadas. Na sequência, a metodologia de Dickey-Fuller Aumentado (DFA) foi empregada, conforme descrito por Enders (2004), para identificação da presença ou não de raiz unitária.

O procedimento sequencial proposto por Enders (2004, p. 203) a partir do teste DFA foi adotado no presente trabalho, com a finalidade de auxiliar na definição correta do modelo a ser utilizado no teste - incluindo ou não a constante e a tendência determinística.

A seguinte formulação foi utilizada:

$$
\Delta y_{t}=\alpha+\beta_{t}+\eta y_{t-1}+\sum_{i=1}^{p-1} \phi_{i} \Delta y_{t-1}+e_{t}
$$

O passo seguinte se deu ao testar a existência de cointegração entre as variáveis, ou seja, a existência de relação de longo prazo entre elas. A metodologia utilizada foi a proposta por Johansen (1988), que busca determinar o ranking (número de vetores de cointegração) através de um VAR de ordem $p$. Testa-se, portanto, a existência de $\mathrm{n}$ vetores de cointegração, e é indicada para modelos com mais de duas variáveis explicativas.

O teste de Johansen em sua natureza é formulado para variáveis integradas de ordem 1, ou I(1), sendo sua formulação matemática expressa pela equação (14) abaixo:

$$
\Delta y_{t}=\sum_{i=1}^{p-1} \Gamma_{i} \Delta y_{t-i}+\Pi y_{t-1}+\mu+\varphi d_{t}+\varepsilon_{t}
$$


em que $\mathbf{y}_{\mathbf{t}}$ é um vetor $(k x 1)$ de variáveis I $(1)$, e o $\varepsilon_{t} \sim N(0, \Sigma)$ e $E\left(\varepsilon t \varepsilon s^{\prime}\right)=0$ para qualquer $t$ diferente de $s$, sendo $\mathbf{d}_{\mathrm{t}}$ um vetor de variáveis binárias para captar a variação estacional.

A matriz de coeficiente de $y_{t-1}$ (matriz $\Pi$ ) possui as informações de longo prazo entre as variáveis. Assumindo-se que o posto desta matriz seja $r, y_{t}$ será estacionário na expressão (9), se $r=k$. Caso $r=0$, П é uma matriz nula e a expressão (9) é estacionária. Por fim, se $0<r<k$, existem matrizes $\alpha$ e $\beta$ de dimensão $k x r$, tais que $\Pi=\alpha \beta$ ' e o vetor $\beta^{\prime} y_{t}$ é estacionário, existindo, assim, $r$ vetores de cointegração, que são exatamente suas $r$ colunas (HARRIS, 1995).

\subsection{Fonte de dados}

Os dados referentes às importações de arroz pelo Brasil foram coletados para quantidade (em toneladas) e valor (US\$ FOB), tanto do produto originado da Argentina, quanto do Uruguai, via sistema Alice da Secex/MDIC.

Os dados obtidos são mensais e divulgados por categorias: arroz em casca, arroz cargo ou castanho e arroz beneficiado ou processado, que incluem o parboilizado e o branco ${ }^{6}$. Após o agrupamento por categoria, aplicou-se uma conversão de todos os dados para equivalente arroz em casca. Desta forma, é possível somar os totais importados desses tipos para cada país de origem. A taxa de conversão de arroz cargo ou castanho para o equivalente arroz em casca é de 1,22; de arroz beneficiado ou processado para equivalente arroz em casca é de $1,47^{7}$.

Cumprida esta etapa, opta-se por estimar um modelo único para analisar os determinantes de demanda por importação dos dois países, ou seja, definindo um modelo para demanda de arroz do Brasil, oriundo do Mercosul. Desta forma, foram somadas as quantidades totais mensais do arroz importado dos dois países (em equivalente casca), convertidas em sacas de $50 \mathrm{~kg}$. O último tratamento dado a esta série foi a sua trimestralização, tendo como início da série os dados de janeiro de 1989 (início do $1^{\text {o }}$ trimestre) e final, setembro de 2008 (3o trimestre).

O preço médio pago pelo produto importado mensalmente foi calculado como a razão entre valor (em US\$ FOB) e quantidade importados ${ }^{8}$. Este

6 Optou-se por não considerar a categoria de arroz quebrado, devido à pouca representatividade desta nas importações brasileiras de arroz.

7 Esta taxa equivalente foi obtida através de consulta a pesquisadores do Cepea (Centro de Estudos Avançados em Economia Aplicada), do projeto Indicador Arroz em Casca ESALQ/Bolsa Brasileira de Mercadorias - BVMF.

8 Na ausência de séries de preços de importação de arroz praticados pelos países estudados, o uso do valor médio da importação está embasado em Leamer e Stern (1970). 
valor médio do arroz importado foi calculado somente após a obtenção dos equivalentes do arroz importado em casca, de sua totalização e transformação para dados trimestrais.

Para se obter o preço médio de importação que represente ambos os países parceiros, foi calculado o peso de cada um deles no total importado do Mercosul pelo Brasil, usando a parcela do volume adquirido (equivalente casca) de cada um em relação ao total importado. Esse peso foi assumido como a participação de cada país no cálculo do preço médio trimestral. Após a formação dessa série de preços médios trimestrais para o Mercosul, dados em US\$/saca de $50 \mathrm{~kg}$, deflacionou-se a série a partir do IPC americano, com base em setembro de 2008.

Os preços domésticos utilizados são dados da $\mathrm{FGV}^{9}$, para o preço do arroz em casca recebido pelo produtor do Rio Grande do Sul, escolhido por ser o maior produtor nacional do cereal. Esta série foi deflacionada pelo IGP-DI e trimestralizada.

Ainda, as informações macroeconômicas de renda e taxa de câmbio foram coletadas do IBGE (Instituto Brasileiro de Geografia e Estatística)e do Banco Central do Brasil.

Em relação à renda, assumiu-se a série dos rendimentos médios dos trabalhadores da região metropolitana de São Paulo, calculada pelo Dieese e divulgada pelo IBGE. Esta série foi trimestralizada e deflacionada pelo IGP-DI, com base em setembro de 2008.

A taxa de câmbio adotada foi a série da taxa de câmbio real, mensal, em R\$/US\$, disponibilizada no Banco Central, também trimestralizada para esta análise.

Por fim, a série do IGP-DI (Índice Geral de Preços - Disponibilidade Interna) da FGV, foi coletada no sítio do Ipea (Instituto de Pesquisas Econômicas Aplicadas).

\section{Resultados}

Os resultados a seguir foram obtidos através da estimação do modelo de excesso de demanda doméstica de arroz, estruturado em um VAR Estrutural,

\footnotetext{
9 A opção pelos dados desta instituição se deu pelo fato de possuírem uma série mais extensa. Foi analisada a correlação entre estes dados e série de preços de arroz em casca no mercado interno, disponibilizada pela Conab, para o período de 1995 a 2008, ambos a preços recebidos pelo produtor no RS. O coeficiente de correlação calculado foi de 0,975 .
} 
compreendendo as variáveis quantidade de importação, preço doméstico, preço de importação, renda interna e taxa de câmbio ${ }^{10}$.

Conforme abordado anteriormente, para a realização dos testes de raiz unitária, utiliza-se o procedimento proposto por Enders (2004), que recomenda que se inicie o teste da forma mais geral (em nível, com constante e tendência), eliminando progressivamente os termos determinísticos, sempre que não se apresentarem significativos, diferenciando as séries, se necessário. Os resultados dos testes apresentados a seguir foram obtidos com a utilização dos softwares estatísticos RATS, versão 3.2, e E-Views, versão 5.0.

Como todas as séries foram transformadas em logaritmo, as variáveis são representadas com a seguinte notação: $l M d=$ logaritmo da quantidade importada; $l P d=$ logaritmo do preço do arroz doméstico; $l Y d=$ logaritmo da renda doméstica; $l P m=$ logaritmo do preço do arroz importado (em US\$); $l E=$ logaritmo da taxa de câmbio real.

No teste DFA, o número de defasagens necessárias a serem incluídas na autorregressão é estimado de forma a eliminar a autocorrelação dos resíduos. Para tanto, a ordem do processo autorregressivo (AR) foi determinada de acordo com os menores valores apontados pelos critérios de AIC e SBC.

Os resultados obtidos pelo teste da raiz unitária são apresentados na Tabela 1. Os testes de AIC e SBC sugerem um modelo autorregressivo de ordem 6 - AR(6) para as variáveis $l M d$ e $l Y d$, de ordem 5 - AR(5) para a variável $l P d$, e de ordem 1 - AR(1) para as demais variáveis.

Os resultados do teste DFA indicam que, em nível, todas as séries são integradas de ordem 1 - I(1), à exceção da série de preço doméstico $(l P d)$. Ao repetir o ajustamento para as séries na primeira diferença, todas as séries são $\mathrm{I}(1)$, com coeficientes significativos a $1 \%$.

A variável preço doméstico de arroz $(l P d)$ sinaliza estacionariedade em nível, porém, devido à proximidade dos valores calculados com os da tabela de valores críticos, optou-se por utilizá-la na primeira diferença. Desta forma, a partir de agora, a série de preços domésticos de arroz será diferenciada e tratada como estacionária apenas na primeira diferença. Sendo assim, este trabalho prosseguirá com a realização do teste de cointegração entre as séries analisadas.

10 Estimou-se, também, um modelo sem a inclusão da taxa de câmbio, e, portanto, no qual os preços de importação foram dados em R\$. Porém, como todos os resultados se comportaram de maneira similar, neste artigo apresenta-se apenas o modelo mais completo, que possibilita interpretar as relações e os impactos das variáveis preço de importação e taxa de câmbio, separadamente. A importância desta desagregação do preço de importação internalizado nestes dois componentes, taxa de câmbio e preço internacional pode ser verificada pelos resultados dos choques na taxa de câmbio sobre as importações de arroz. 
Tabela 1. Resultados dos testes de raiz unitária DFA em nível e na primeira diferença, para as variáveis $l M d, l P d, l Y d, l P m$ e $l E$, entre 1989 a 2008.

\begin{tabular}{cccccccc}
\hline \multirow{2}{*}{ Séries } & $\begin{array}{c}\text { Defasagem } \\
(\mathbf{p}-1)\end{array}$ & $\tau_{\tau}$ & $\tau_{\beta_{\tau}}$ & $\tau_{\mu}$ & $\tau_{\alpha_{\mu}}$ & $\tau$ & \multicolumn{1}{c}{ Estatísticas } \\
\cline { 3 - 8 } & 6 & $-1,490$ & $-1,069$ & $-2,503$ & 2,492 & 0,777 & $-6,109^{* *}$ \\
$l M d$ & 5 & $-4,591^{* *}$ & $-3,311^{*}$ & $-2,971^{*}$ & $2,962^{*}$ & $-0,591$ & $-4,700^{* *}$ \\
$l P d$ & 6 & $-2,095$ & $-2,087$ & $-0,156$ & 0,109 & $-1,045$ & $9,925^{* *}$ \\
$l Y d$ & 1 & $-1,520$ & $-0,324$ & $-1,942$ & 1,944 & $-0,106$ & $-6,378^{* *}$ \\
$l P m$ & 1 & $-1,591$ & 0,750 & $-1,611$ & 1,898 & $-0,124$ & $-8,717^{* *}$ \\
$l E$ & 1 &
\end{tabular}

Nota: Valores críticos para as estatísticas descritas, obtidos em Enders (2004), são, respectivamente: $-4,09,3,56$, -3,54, 3,24, -2,61 em nível de significância de 1\% e; -3,47, 2,8, -2,91, 2,55, -1,95 a 5\% de significância.

* Significativo a $5 \%$.

** Significativo a $1 \%$.

Fonte: Dados da pesquisa.

O número de defasagens utilizadas nos testes de cointegração (uma defasagem) foi definido de acordo com o critério de AIC, SBC e HQ, para uma versão multiequacional. A especificação indicada para o teste foi o modelo sem intercepto e sem tendência determinística.

Conforme apresentado na Tabela 2, os testes de máximo autovalor e do traço apresentam valores significativos a partir da hipótese nula de que não há vetor de cointegração $(r \leq 0)$, contra a hipótese alternativa de que existe um vetor de cointegração $(r=1)$. Desta maneira, deve ser considerada no modelo a existência de um vetor de cointegração.

Tabela 2. Resultados dos testes de cointegração de Johansen entre as séries $l M d, l P d, l P m, l Y d$ e $l E$.

\begin{tabular}{cccc}
\hline Hipótese Nula & Hipótese Alternativa & $\boldsymbol{\lambda} \max$ & $\boldsymbol{\lambda}$ traço \\
\hline $\mathrm{r} \leq 0$ & $\mathrm{r}=1$ & $35,3379^{*}$ & $70,5654^{*}$ \\
$\mathrm{r} \leq 1$ & $\mathrm{r}=2$ & 17,89318 & 35,22743 \\
$\mathrm{r} \leq 2$ & $\mathrm{r}=3$ & 9,822310 & 17,33426 \\
$\mathrm{r} \leq 3$ & $\mathrm{r}=4$ & 5,550328 & 7,511946 \\
$\mathrm{r} \leq 4$ & $\mathrm{r}=5$ & 1,961618 & 1,961618 \\
\hline
\end{tabular}

Nota: Modelo sem tendência determinística e com constante restrita, ajustado com três defasagens.

* Significativo a $1 \%$.

Fonte: Dados da pesquisa.

Assim, os resultados do teste de cointegração entre as cinco séries do modelo apontam que existem relações de equilíbrio de longo prazo entre as variáveis, de modo que deve ser ajustado por um modelo VAR, e incluir um termo de Correção de Erro (VEC), de forma a considerar tanto os aspectos de curto quanto os de longo prazo. 


\subsection{Decomposição da variância do erro de previsão}

O modelo analisado foi construído com a seguinte sequência de variáveis: quantidade de arroz importado, preço doméstico de arroz, preço de importação de arroz (em US\$), renda interna e taxa de câmbio real. Além de um vetor de correção de erros, também adicionou-se as quatro variáveis binárias mencionadas na descrição do modelo empírico.

A matriz de relações contemporâneas apresenta as relações entre as variáveis, selecionadas na definição do modelo VAR estrutural, cujos resultados constam na Tabela 3.

Os sinais dos coeficientes das variáveis analisadas estão de acordo com o esperado. Estes sugerem que aumentos na taxa de crescimento do preço doméstico de arroz levam a um aumento na taxa de crescimento da quantidade importada do cereal, enquanto que aumentos na taxa de crescimento do preço de importação reduzem a taxa de crescimento das importações e elevam a taxa de crescimento do preço doméstico do cereal.

Tabela 3. Coeficientes estimados pela matriz de relações contemporâneas, através de um Vetor de Correção de Erros, dados trimestrais.

\begin{tabular}{|c|c|c|c|c|}
\hline \multicolumn{2}{|c|}{ Relações Contemporâneas } & \multirow{2}{*}{$\begin{array}{l}\text { Coeficientes } \\
\text { Estimados* }\end{array}$} & \multirow{2}{*}{ Desvio Padrão } & \multirow{2}{*}{ Valor $\mathbf{t}^{* *}$} \\
\hline De & Sobre & & & \\
\hline Preços Domésticos & Volume Importado & 2,16893 & 0,48372 & 4,48386 \\
\hline Preços de Importação & Volume Importado & $-1,52870$ & 0,57712 & 2,64884 \\
\hline Renda Interna & Volume Importado & $-1,30502$ & 1,24283 & 1,05004 \\
\hline Taxa de Câmbio & Volume Importado & $-1,74367$ & 0,59832 & 2,91427 \\
\hline Preços de Importação & Preços Domésticos & 0,67019 & 0,11140 & 6,01629 \\
\hline
\end{tabular}

* Os sinais já estão analisados da forma contrária à apresentada pela estimação do modelo.

** Valores apresentados em módulo.

Fonte: Dados da pesquisa.

Já as variações positivas na taxa de crescimento da taxa de câmbio nacional levam a uma redução na taxa de crescimento da quantidade de arroz importado pelo Brasil. O único coeficiente que não apresenta o sinal esperado é relativo à taxa de crescimento da renda interna, indicando que aumentos na mesma reduzem contemporaneamente a taxa de crescimento do volume importado ${ }^{11}$. Entretanto, este coeficiente não é significativo estatisticamente.

11 A variável PIB também foi testada em um modelo preliminar, porém, além da presença de acentuada quebra estrutural em 1994, seu ajustamento foi não satisfatório nos testes apresentados, com pior significância e maior amplitude entre os coeficientes resultantes da matriz de relações contemporâneas estimada. Optou-se, assim, na utilização da série rendimento médio do trabalhador assalariado na RMSP no modelo 
Desconsiderando-se, porém, a significância deste coeficiente e partindo-se da premissa do modelo apresentado na equação (7), de que as importações de arroz são decorrentes do excedente de demanda, pode-se presumir que o arroz é um bem de consumo inferior. Ou seja, um aumento na renda da população eleva o consumo de seus produtos substitutos, e leva, consequentemente, a uma redução no excedente da demanda interna de arroz e nas importações deste produto. Este fator refletiria, assim, em uma redução dos preços domésticos.

A inclusão das quatro dummies no modelo contribui para um melhor ajustamento do modelo. Essa inclusão favorece um resultado mais evidente do efeito da variável taxa de câmbio no modelo, bem como torna mais intensa a influência do câmbio sobre as variáveis quantidade de importação e preço doméstico.

Analisando-se a decomposição da variância do erro de previsão de cada variável, verifica-se que nas variáveis quantidade de importação de arroz, preço doméstico de arroz e preço de importação de arroz, há exogeneidade em relação às demais variáveis do modelo, ou seja, cada uma dessas variáveis é explicada, principalmente, por ela mesma.

O volume importado (Tabela 4) responde por aproximadamente $67,7 \%$ das variações nas importações de arroz, considerando-se a média de quatro trimestres; o preço doméstico (Tabela 5), a $63 \%$ das variações nele mesmo; e o preço de importação, a 87,7\% de suas variações (Tabela 6).

Um ponto que chama a atenção na análise dos determinantes de importação de arroz do Brasil está ligado ao preço doméstico de arroz e à taxa de câmbio, que explicam a importação do cereal em 17,7\% e 8,4\% respectivamente.

O preço doméstico chama a atenção, pois, além de ratificar a fundamentação do modelo teórico, demonstra que há uma relação relevante dos preços de arroz no mercado brasileiro, especificamente no Rio Grande do Sul, sobre o volume de arroz importado pelo país. Em outras palavras, agentes atuantes nesta cadeia respondem em parte às oscilações de preços no mercado doméstico, para optar por complementar ou formar estoques com arroz importado. Quanto ao efeito da taxa de câmbio, embora menos intenso, vê-se que também é um mecanismo importante para determinar o comportamento dos agentes produtores e comercializadores de arroz no Brasil.

Já o preço de importação do arroz e renda interna explicam 2,9\% e 3,2\% respectivamente, das importações de arroz ao longo do período, mostrando-se pouco relevantes se comparados ao preço doméstico (Tabela 4).

Outra constatação importante é a influência do preço de importação sobre o preço doméstico de arroz. O primeiro explica cerca de 31,2\% das variações

empírico apresentado, como melhor proxy para captar o efeito renda sob a demanda por importação de arroz pelo Brasil. 
do preço doméstico ao longo do período, enquanto que o volume de arroz importado, renda interna e taxa de câmbio, explicam, nessa ordem, 0,5\%, 1,7\% e 3,6\% das variações no preço doméstico (Tabela 5).

Estes resultados sugerem uma relação mais forte entre o preço de importação e o preço doméstico, e deste último com a demanda por volume de importações. Contudo, quanto ao preço de importação, este é pouco explicado pelas demais variáveis, o que pode ser reflexo da maior inserção do Mercosul no mercado internacional de arroz, sobretudo do Uruguai. Isto pode representar que os preços destes países têm refletido, pelo menos em parte, as oscilações nos preços internacionais, reduzindo, assim, a dependência e risco de preços em relação aos movimentos na cadeia orizícola brasileira.

Entretanto, de forma a melhor fundamentar estas conclusões, no próximo tópico são analisadas as funções impulso-resposta em cada uma das variáveis sobre as demais, o que permite estimar por quanto tempo os efeitos dos choques permanecem atuantes sobre as variáveis em estudo.

Tabela 4. Decomposição da variância do erro de previsão para as quantidades de arroz importado - $\mathrm{DlM}_{\mathrm{d}}$ - do Mercosul pelo Brasil.

\begin{tabular}{ccccccc}
\hline \multirow{2}{*}{ Trimestres } & \multirow{2}{*}{ Desvio Padrão } & \multicolumn{5}{c}{ Decomposição da variância devido a choque em (\%) } \\
\cline { 3 - 7 } & & DlM $_{\mathbf{d}}$ & DIP $_{\mathrm{d}}$ & DlP $_{\mathrm{m}}$ & DIY $_{\mathrm{d}}$ & DlE \\
\hline 1 & 0,4804 & 68,9680 & 20,2660 & 0,0260 & 1,0780 & 9,6620 \\
2 & 0,5197 & 68,1840 & 17,4750 & 3,4880 & 2,5320 & 8,3210 \\
3 & 0,5276 & 67,5330 & 17,2570 & 3,4130 & 3,6070 & 8,1900 \\
4 & 0,5292 & 67,4330 & 17,1980 & 3,4190 & 3,7690 & 8,1810 \\
\hline
\end{tabular}

Nota: VAR Estrutural, Processo de Bernanke $-\mathrm{DlM}_{d}, \mathrm{DlP}_{\mathrm{d}}, \mathrm{DlP}_{\mathrm{m}}, \mathrm{DlY}_{\mathrm{d}}, \mathrm{DlE}$.

Fonte: Dados da pesquisa.

Tabela 5. Decomposição da variância do erro de previsão para os preços domésticos de arroz do Brasil - $\mathrm{DlP}_{\mathrm{d}}$.

\begin{tabular}{ccccccc}
\hline \multirow{2}{*}{ Trimestres } & \multirow{2}{*}{ Desvio Padrão } & \multicolumn{5}{c}{ Decomposição da variância devido a choque em (\%) } \\
\cline { 3 - 7 } & & DlM $_{\mathrm{d}}$ & DlP $_{\mathrm{d}}$ & DlP $_{\mathrm{m}}$ & DIY $_{\mathrm{d}}$ & DlE \\
\hline \multirow{2}{*}{1} & 0,1214 & 0,0000 & 67,5080 & 32,4920 & 0,0000 & 0,0000 \\
2 & 0,1292 & 0,5370 & 62,2250 & 31,1740 & 1,9470 & 4,1160 \\
3 & 0,1295 & 0,5350 & 62,2970 & 30,9960 & 1,9360 & 4,2370 \\
4 & 0,1296 & 0,5350 & 62,2840 & 30,9870 & 1,9380 & 4,2560 \\
\hline
\end{tabular}

Nota: VAR Estrutural, Processo de Bernanke - $\mathrm{DlM}_{d}, \mathrm{DlP}_{\mathrm{d}}, \mathrm{DlP}_{\mathrm{m}}, \mathrm{DlY}_{\mathrm{d}}, \mathrm{DlE}$.

Fonte: Dados da pesquisa. 
Tabela 6. Decomposição da variância do erro de previsão para os preços de importação de arroz do Mercosul - DILP ${ }_{\mathrm{m}}$ - pagos (em US\$) pelo Brasil.

\begin{tabular}{ccccccc}
\hline \multirow{2}{*}{ Trimestres } & \multirow{2}{*}{ Desvio Padrão } & \multicolumn{5}{c}{ Decomposição da variância devido a choque em (\%) } \\
\cline { 3 - 7 } & & $\mathbf{D l M}_{\mathbf{d}}$ & $\mathbf{D l P}_{\mathbf{d}}$ & $\mathbf{D l P}_{\mathrm{m}}$ & $\mathbf{D l Y}_{\mathbf{d}}$ & DlE \\
\hline 1 & 0,1032 & 0,0000 & 0,0000 & 100,0000 & 0,0000 & 0,0000 \\
2 & 0,1159 & 0,3320 & 9,3610 & 85,7630 & 4,0120 & 0,5320 \\
3 & 0,1161 & 0,3680 & 9,3380 & 85,6310 & 4,0340 & 0,6290 \\
4 & 0,1161 & 0,3700 & 9,3400 & 85,6250 & 4,0350 & 0,6290 \\
\hline
\end{tabular}

Nota: VAR Estrutural, Processo de Bernanke $-\mathrm{DlM}_{\mathrm{d}}, \mathrm{DlP}_{\mathrm{d}}, \mathrm{DlP}_{\mathrm{m}}, \mathrm{DlY}_{\mathrm{d}}, \mathrm{DlE}$.

Fonte: Dados da pesquisa.

\subsection{Função impulso-resposta}

Os resultados obtidos nas estimativas da função impulso-resposta são apresentados nas Figuras 1 a 5, em que se observam as respostas do comportamento das variáveis a choques positivos de $1 \%$ em uma cada uma das variáveis específicas no modelo econômico.

Um choque de $1 \%$ sobre a quantidade importada de arroz causa oscilação nessa quantidade durante os cinco primeiros períodos, com o maior efeito no segundo trimestre, quando ocorre uma queda de aproximadamente 0,40\%. Os impactos deste choque só se anulam após seis trimestres. O choque sobre as quantidades importadas não apresentou efeitos relevantes sobre o comportamento das demais variáveis.

Figura 1. Função de impulso-resposta das quantidades de importação de arroz, do preço doméstico de arroz e do preço de importação de arroz, a um impulso nas quantidades de importação de arroz.

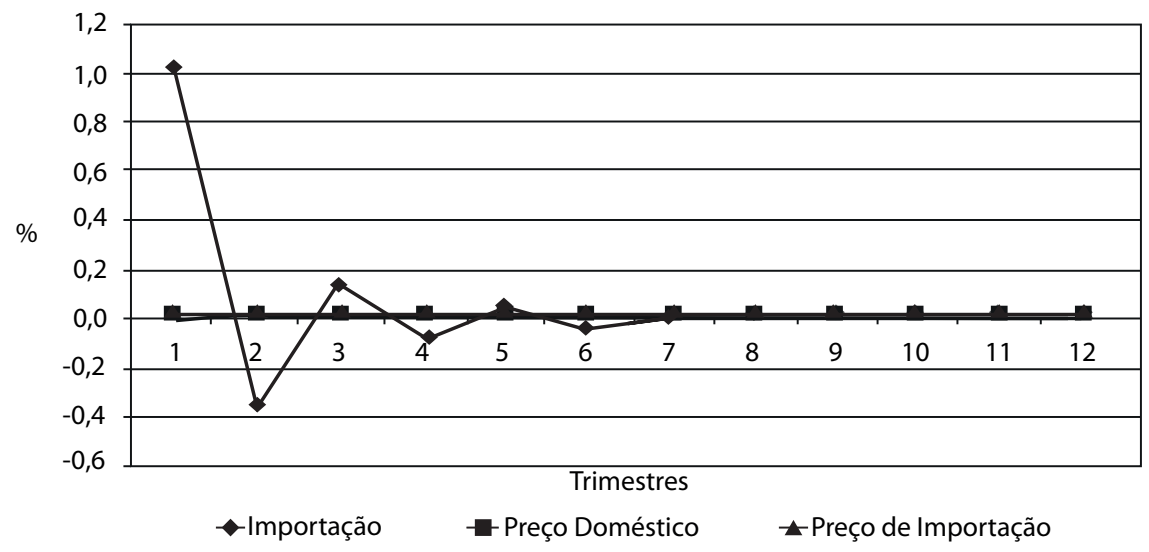

Fonte: Dados da pesquisa. 
Já ao se analisar um choque no preço doméstico de arroz (Figura 2), observa-se uma resposta significativa, com aumento no volume de importação de arroz no primeiro trimestre. A resposta a este impulso eleva em 2,16\% o volume importado. O choque se propaga, ainda provocando, respectivamente, quedas de $0,2 \%$ e $0,28 \%$ e aumento de $0,11 \%$ nas importações do segundo, terceiro e quarto trimestres, até sua dissipação total.

Nota-se, assim, alta sensibilidade das importações a um choque no preço doméstico, o que reforça os argumentos apresentados no modelo de excedente de demanda interna, segundo o qual aumentos na demanda interna de arroz elevam seu preço doméstico e causam um aumento na demanda pelo produto importado. Além disso, este resultado provê maior embasamento das conclusões obtidas pela decomposição da variância.

Constata-se que o preço doméstico é uma variável de importância para explicar os fluxos de importação de arroz brasileiro, e que os agentes atuantes nesta cadeia são sensíveis a oscilações nos preços domésticos e imediatamente respondem a choques nesta variável, de modo a formar ou complementar estoques no mercado interno.

Em relação aos impactos do choque do preço doméstico sobre o preço de importação (Figura 2), verifica-se uma elevação deste em cerca de $0,35 \%$ no segundo trimestre, o que é possivelmente um reflexo do aumento da demanda por arroz no trimestre anterior, por sua vez ocasionada pela elevação dos preços internos de arroz. Com relação aos impactos sobre a própria variável, preço doméstico de arroz, o choque de $1 \%$ no primeiro momento continua no segundo trimestre, com $0,21 \%$, seguido de uma leve redução de $0,08 \%$ no terceiro trimestre até sua dissipação completa antes de um ano.

Figura 2. Função de impulso-resposta das quantidades de importação de arroz, do preço doméstico de arroz e do preço de importação de arroz, a um impulso no preço doméstico de arroz.

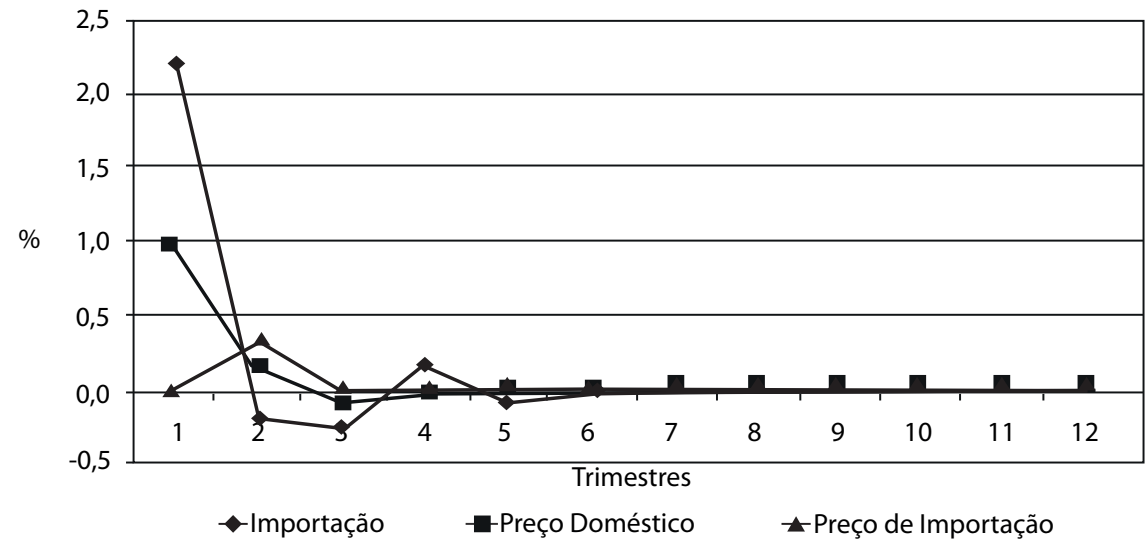

Fonte: Dados da pesquisa. 
No que tange a um choque no preço de importação de arroz de $1 \%$ positivo (Figura 3), observa-se que os efeitos reduzem o volume importado do cereal em significativo $0,93 \%$ no segundo trimestre, e praticamente se dissipam a partir de então, com as elasticidades se aproximando de zero. Este é um importante resultado, pois apesar de os agentes atuantes no setor orizícola nacional responderem rapidamente a variações no preço doméstico para aumentar seus estoques, um choque no preço de importação sobre o volume importado de arroz é mais ameno e um período posterior se comparado ao choque no preço doméstico.

Este comportamento evidencia que parte dos agentes no Brasil apresenta relativa dependência do arroz importado, o que não lhes permite reverter abruptamente sua demanda por arroz do Mercosul, substituindo-o imediatamente por arroz brasileiro. Acredita-se que esta perda de flexibilidade ocorre principalmente por já estarem com contratos firmados tanto com produtores estrangeiros, quanto com as indústrias beneficiadoras no curto prazo. Além disso, há os custos operacionais de se buscar, de imediato, fornecedores de arroz nacional com qualidade compatível à demandada.

O choque de $1 \%$ no preço de importação ocasiona ainda um discreto aumento no próprio preço de importação no segundo trimestre, em torno de $0,28 \%$, e se estabiliza próximo a zero a partir do quarto trimestre.

Ainda, os impactos deste choque no preço de importação sobre o preço doméstico são positivos nos dois primeiros trimestres, respectivamente $0,67 \%$ e $0,19 \%$, ratificando o que se observou nos resultados da decomposição da variância, em que o preço de importação explica relativa parcela do preço doméstico. Desta forma, deve-se salientar, portanto, que um choque no preço doméstico afeta o preço de importação na mesma magnitude que o inverso, levando a uma relação de bicausalidade entre o preço doméstico e o preço de importação de arroz do Mercosul, constatando que um reage ao outro na mesma direção.

Figura 3. Função de impulso-resposta das quantidades de importação de arroz, do preço doméstico de arroz e do preço de importação de arroz, a um impulso no preço de importação de arroz.

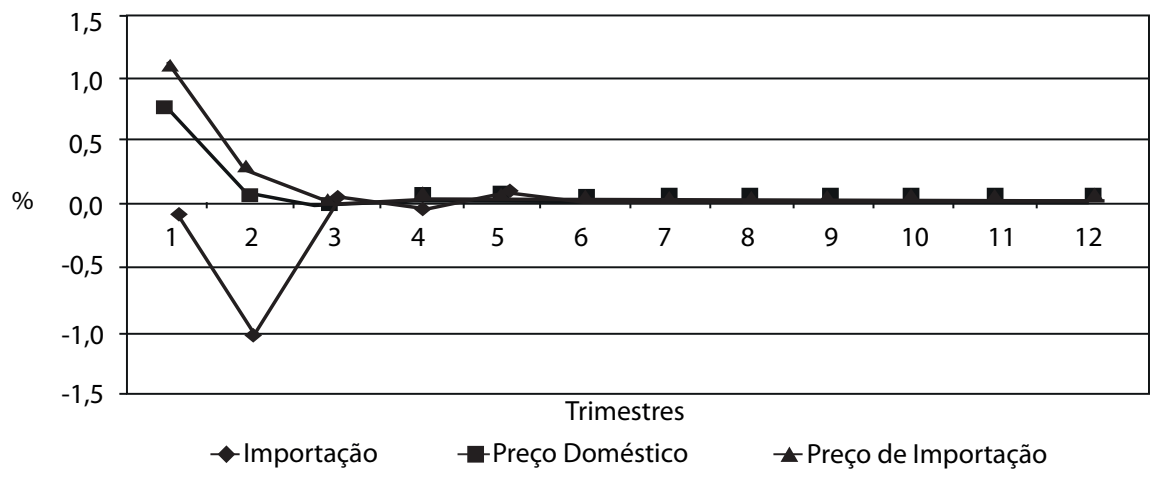

Fonte: Dados da pesquisa. 
Já um choque na renda interna (Figura 4) tem efeito oscilatório sobre o volume de importação de arroz, com efeitos acentuados de queda e aumento, alternados ao longo do primeiro ano, dissipando-se somente após cerca de seis trimestres, ou seja, um ano e meio. Entretanto, cabe lembrar que a renda se mostrou não significativa estatisticamente para a determinação do volume de importação.

Por outro lado, os impactos do impulso na renda, tanto sobre o preço doméstico, quanto sobre o preço de importação, são positivos. No preço doméstico, o choque provoca aumento de $0,47 \%$ no segundo trimestre, enquanto que no preço de importação, o efeito é de aproximadamente $0,60 \%$ e $0,05 \%$ no segundo e terceiro trimestres.

Figura 4. Função de impulso-resposta das quantidades de importação de arroz, do preço doméstico de arroz, do preço de importação de arroz e da renda interna, a um impulso na renda interna brasileira.

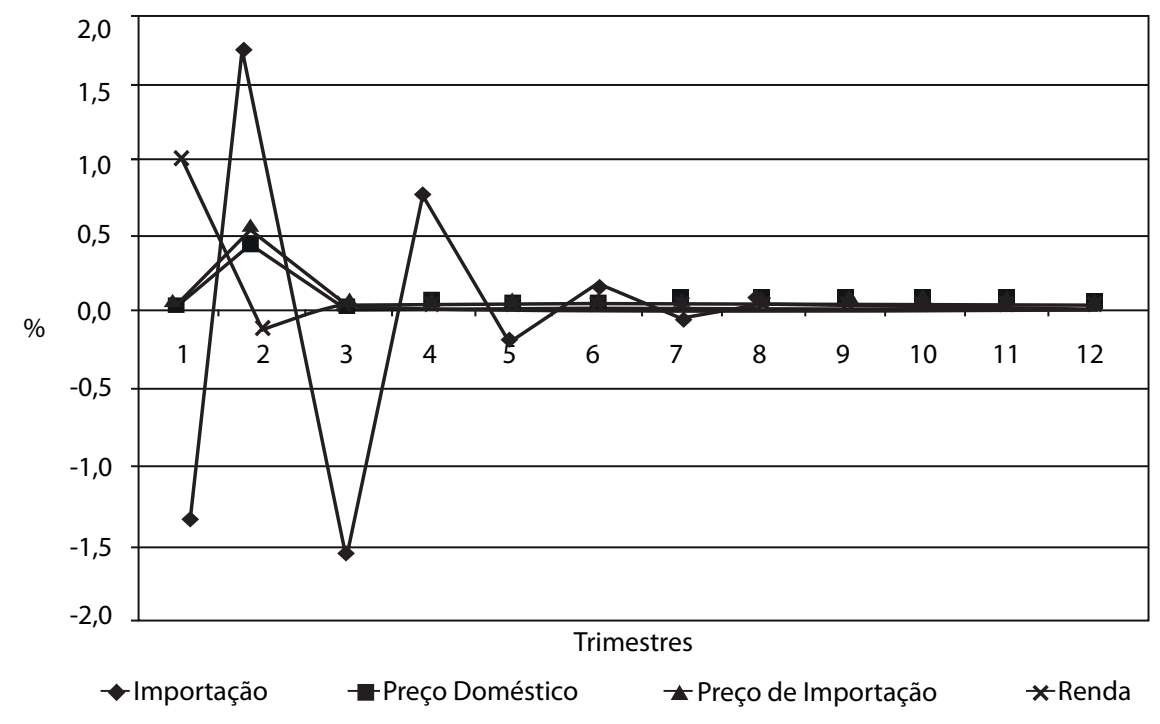

Fonte: Dados da pesquisa.

Finalmente, é importante apresentar o resultado da função impulso-resposta para a taxa de câmbio real (Figura 5). Um choque positivo de 1\% sobre esta variável acarreta redução expressiva imediata nas quantidades importadas de arroz, de 1,75\% logo no primeiro trimestre, seguida de reduções de $0,15 \%$ e $0,12 \%$ no segundo e quarto trimestres, respectivamente. Portanto, a sensibilidade das importações de arroz a variações na taxa de câmbio é considerável, sendo esta relação ainda mais evidente do que quando analisada somente a decomposição da variância. 
Da mesma forma que variações positivas nos preços domésticos tendem a aumentar a importação brasileira de arroz, variações positivas na taxa de câmbio as reduzem, com magnitude e periodicidade semelhante, incitando à compreensão de que agentes atuantes na comercialização de arroz no Brasil são sensíveis à desvalorização do Real, reduzindo rapidamente o volume importado, como forma de minimizar seus custos na aquisição do cereal importado.

O efeito do choque na taxa de câmbio sobre o preço doméstico também é significativo. Esse efeito é de aumento no segundo trimestre $(0,30 \%)$, se anulando a partir de então. $\mathrm{O}$ fato de a demanda por importação se reduzir de imediato, a partir da desvalorização cambial, deve elevar a procura pelo cereal produzido internamente, o que é repassado, em menor escala, aos períodos subsequentes.

Por outro lado, o preço de importação é pouco afetado por choques na taxa de câmbio, muito provavelmente pela influência dos preços internacionais de arroz dos países exportadores do Mercosul, sobretudo o Uruguai. Nesse país, onde é baixo o consumo per capita doméstico, é possível para os agentes adotarem estratégias de priorizar o abastecimento do mercado brasileiro ou do restante do mercado internacional, em períodos diferentes, de acordo com a sazonalidade de oferta em cada um de seus parceiros comerciais.

Figura 5. Função de impulso-resposta das quantidades de importação de arroz, do preço doméstico de arroz, do preço de importação de arroz da renda interna e da taxa de câmbio, a um impulso na taxa de câmbio.

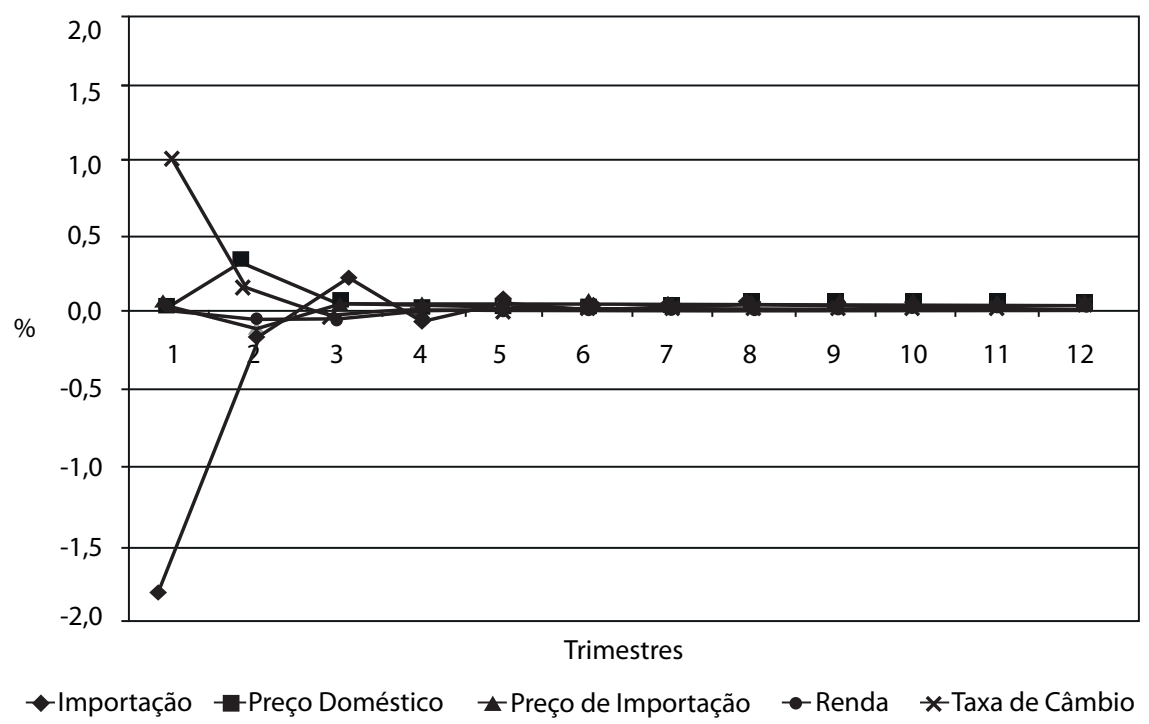

Fonte: Dados da pesquisa. 
Desta forma, este trabalho confirma que, também para o caso do arroz, a variável taxa de câmbio mostra-se fundamental para análises dos fluxos das importações brasileiras oriundas do Mercosul.

\section{Conclusões}

A taxa de câmbio e os preços domésticos do arroz mostraram-se como as principais variáveis determinantes da demanda por importação de arroz no Brasil.

Os resultados estimados pelo modelo econômico proposto, de maneira geral, são satisfatórios, com os coeficientes apresentando os sinais esperados, e estatisticamente significativos. A exceção se deu com a variável renda interna, representada pela proxy rendimento dos trabalhadores assalariados na RMSP, cujo sinal invertido pode indicar que o arroz é um bem de consumo inferior.

A decomposição da variância evidencia uma forte relação entre o volume importado de arroz do Mercosul e o preço doméstico do cereal no Brasil. A influência do preço doméstico sobre as importações confirma a importância da análise do mercado interno para entender a dinâmica deste fluxo comercial.

Adicionalmente, o preço doméstico tem influência significativa do preço de importação do arroz do Mercosul, representativo do produto importado do Uruguai e da Argentina, enquanto que esta variável tem moderada influência do preço doméstico brasileiro. Assim, este preço do produto importado afeta não só os volumes comprados pelo Brasil, mas também o nível de preços praticados no mercado nacional. Embora haja bicausalidade, os preços do produto brasileiros afetam com menor intensidade os preços do produto importador do que o contrário.

A inclusão da taxa de câmbio no modelo também evidencia relações interessantes. Esta variável mostra-se determinante para as importações brasileiras de arroz, além de ter influência sobre o preço doméstico do cereal.

A estimação da função impulso-resposta possibilita a obtenção das elasticidades-respostas das variáveis analisadas no modelo a choques positivos não antecipados sobre elas próprias. Observa-se o comportamento destas variáveis a estes choques, como no caso do volume de importação, que respondeu fortemente a mudanças no preço doméstico, no preço de importação e na taxa de câmbio e apresentou maior sensibilidade a fatores não antecipados.

$\mathrm{O}$ fato de o choque de um aumento no preço de importação afetar o volume importado apenas no segundo trimestre pode ser consequência de uma inflexibilidade no curto do prazo por parte dos agentes importadores em realizar ajustamentos nas suas transações. Isso é decorrente da existência de acordos e contratos pré-estabelecidos com atacadistas e varejistas no mercado brasileiro, que dificulta que os importadores efetuem redução imediata nos volumes importados em resposta ao choque nos preços externos. Já no caso 
de um aumento no preço doméstico, há uma resposta no volume de arroz importado logo no primeiro trimestre.

A resposta a uma desvalorização cambial (impulso positivo na taxa de câmbio), por sua vez, foi imediata, com redução de quase duas vezes no volume importado de arroz, e com um consequente aumento no preço doméstico no primeiro trimestre posterior ao choque. Isso mostra que agentes atuantes no setor orizícola brasileiro têm comportamento similar, mas inversamente proporcional, em relação à valorização da taxa de câmbio e aos aumentos nos preços domésticos, com respostas imediatas na redução e aumento das importações, respectivamente.

O preço doméstico também reage rapidamente a choques no preço do arroz importado, embora a reação do preço de importação a variações no preço brasileiro é ainda mais evidente, mostrando que, por um lado, os países ofertantes de arroz no Mercosul estão mais integrados ao mercado internacional, e por outro, que parte dos demandantes de arroz importado no Brasil compram na Argentina e Uruguai em virtude do excesso de demanda doméstica.

Estas respostas aos choques no preço doméstico sobre o preço de importação e vice-versa indicam que há uma relação bicausal entre esses dois preços, e mostra que o mercado é integrado, ou seja, seus agentes reagem rapidamente a alterações positivas em qualquer um dos mercados, embora com magnitudes diferentes.

Conclusivamente, o presente artigo pode ser considerado como uma contribuição à literatura, à medida que, através de um ferramental econométrico, produz elementos para um melhor entendimento da demanda por importação brasileira de arroz do Mercosul, assunto bastante debatido entre agentes da cadeia agroindustrial de arroz do Brasil e frequentemente alvo de demandas destes à intervenção do governo.

Pesquisas posteriores podem ser embasadas a partir dos resultados aqui apresentados como, por exemplo, a estimação de um modelo de oferta de exportação de arroz do Mercosul para o Brasil, adicionando as taxas de câmbio tanto da Argentina quanto do Uruguai e detalhamentos sobre a qualidade do produto comercializado. Cabe ainda a análise da influência dos preços internacionais de arroz sobre a oferta de exportação destes países, sobretudo em período mais recente, principalmente no Uruguai, cujo número de parceiros comerciais aumentou nos últimos anos. Ainda, deve-se incentivar um estudo que tente avaliar os efeitos da intervenção governamental sobre o setor orizícola, no contexto do problema analisado neste artigo.

Outro estudo futuro de relevância para o setor é analisar a causalidade entre os preços domésticos de cada um destes países, de forma a estimar o grau de influência entre estes mercados. Este estudo enfrenta, ainda, a dificuldade de obter séries de dados de preços domésticos na Argentina e Uruguai, metodologicamente bem embasadas, e com periodicidade extensa, como a brasileira, que viabilizem uma análise consistente. 


\section{Referências Bibliográficas}

ASOCIACIÓN DE CULTIVADORES DE ARROZ - ACA. El cultivo en Uruguay: datos de interés. Montevideo, 2008. Disponível em: http://www.aca.com.uy/el_ cultivo.html. Acesso em: 3 set. 2008.

ADAMI, A.C.O. Contratos de opção: análise do potencial de sustentação de preços para o mercado de arroz. 2005. 117 p. Dissertação (Mestrado em Economia Aplicada) - Escola Superior de Agricultura "Luiz de Queiroz", Universidade de São Paulo, Piracicaba, 2005.

ALVES, L.R.A. Transmissão de preços entre produtos do setor sucroalcooleiro do Estado de São Paulo. 2002. 107 p. Dissertação (Mestrado em Economia Aplicada) Escola Superior de Agricultura "Luiz de Queiroz", Universidade de São Paulo, Piracicaba, 2002.

ALVES, L.R.A. A reestruturação da cotonicultura no Brasil: fatores econômicos, institucionais e tecnológicos. 2006. 121 p. Tese (Doutorado em Economia Aplicada) - Escola Superior de Agricultura "Luiz de Queiroz", Universidade de São Paulo, Piracicaba, 2006.

ARGENTINA. Ministerio de Economia y Finanzas Públicas. Secretaria de Agricultura, Ganadería, Pesca y Alimentos - SAGPyA. Subsecretaria de Economia Agropecuaria. Informe de productos regionales: arroz. Buenos Ayres, 2007. Disponível em: http://www.sagpya.mecon.gov.ar. Acesso em: 1 set. 2008.

BACCHI, M.R.P. Previsão de preços de bovino, suino e frango com modelos de séries temporais. 1994. 172 p. Tese (Doutorado em Economia Aplicada) - Escola Superior de Agricultura “Luiz de Queiroz", Universidade de São Paulo, Piracicaba, 1994.

BARATA, T.S. Caracterização do consumo de arroz no Brasil: um estudo na Região Metropolitana de Porto Alegre. 2005. 93 p. Dissertação (Mestrado em Agronegócios) - Centro de Estudos e Pesquisas em Agronegócios, Universidade Federal do Rio Grande do Sul, Porto Alegre, 2005.

BARROS, G.S.C.; BACCHI, M.R.P.; BURNQUIST, H.L. Estimação de equações de oferta de exportação de produtos agropecuários para o Brasil (1992/2000). Brasília: Instituto de Pesquisa Econômica Aplicada - IPEA, mar. 2002. 53 p. (Texto para discussão, 865).

BANCO CENTRAL DO BRASIL - BACEN. Sistema gerenciador de séries temporais. Disponível em: http://www4.bcb.gov.br/?SERIESTEMP. Acesso em: 5 dez. 2008.

BRASIL. Ministério da Agricultura, Abastecimento e Agropecuária - MAPA. Dados estatísticos. Disponível em: http://www.agricultura.gov.br. Acesso em: 14 ago. 2008a. 
BRASIL. Ministério do Desenvolvimento, Indústia e Comércio Exterior - MDIC. Secretaria de Comércio Exterior - SECEX. ALICEWEB. Disponível em: http:// www.aliceweb.desenvolvimento.gov.br. Acesso em: 4 dez. 2008 b.

CARVALHO, A.; NEGRI, J.A. de. Estimação de equações de importação e exportação de produtos agropecuários para o Brasil (1977/1998). Brasília: Instituto de Pesquisa Econômica Aplicada - IPEA, jan. 2000. 32 p. (Texto para discussão, 698).

CARVALHO, A.; PARENTE, M.A. Estimação das equações de demanda de importações por categoria de uso para o Brasil (1978/1996). Brasília: Instituto de Pesquisa Econômica Aplicada - IPEA, abr. 1999. 33 p. (Texto para discussão, 636).

CASTRO, A.S. de; CAVALCANTI, M.A.F.H. Estimações das equações de exportação e importação para o Brasil - 1955/95. Rio de Janeiro: Instituto de Pesquisa Econômica Aplicada - IPEA, mar. 1997. 58 p. (Texto para discussão, 469).

COMPANHIA NACIONAL DE ABASTECIMENTO - CONAB. Safras: séries históricas. Brasília, 2008a. Disponível em: http://www.conab.gov.br/conabweb/ download/safra/ArrozSerieHist.xls. Acesso em: 26 jul. 2008.

DIB, M.F.S.P. Importações brasileiras: políticas de controle e determinantes da demanda. 1987. 177 p. Dissertação (Mestrado em Economia do Setor Público) Pontifícia Universidade Católica do Rio de Janeiro, Rio de Janeiro, 1987.

DICKEY, D.A.; FULLER, W.A. Likelihood ratio statistics for autoregressive time series with a unit root. Econometrica, Chicago, v. 49, n. 4, p. 1057-1072, July 1981.

DICKEY, D.A.; PANTULA, S. Determining the order of differencing in autoregressive processes. Journal of Business and Economics Statistics, Chicago, v. 3, n. 5, p. 455-61, 1987.

ENDERS, W. Applied econometrics time series. 2. ed. New York: Wiley, 2004. p. 460.

FOOD AND AGRICULTURAL ORGANIZATION - FAO. FAOSTAT: statistics datas. 2008. Disponível em: http://faostat.fao.org/DesktopDefault. aspx?PageID=567\&lang=en. Acesso em: 2 set. 2008.

FERREIRA, C.M.; SOUSA, I.S.F. de; DEL VILLAR, P.M. (Ed.). Desenvolvimento tecnológico e dinâmica da produção de arroz de terras altas no Brasil. Santo Antônio de Goiás: Embrapa Arroz e Feijão, 2005. p. 118.

FUNDAÇÃO GETÚLIO VARGAS - FGV. Informações econômicas online: FGVdados. Disponível em: http://fgvdados.fgv.br/. Acesso em: 25 nov. 2009.

HARRIS, R.I.D.: Using cointegration analysis in econometric modelling. Prentice Hall/Havester Wheatsheaf, 1995, p. 176.

HOUTHAKKER, H.S.; MAGEE; S.P. Income and price elasticities in world trade. The Review of Economics and Statistics, Boston, v. 51, n. 2, 1969. p. 111-125. 
Disponível em: http://www.jstor.org/page/info/about/policies/terms.jsp. Acesso em: 25 out. 2008.

INSTITUTO BRASILEIRO DE GEOGRAFIA E ESTATÍSTICA - IBGE. Sistema IBGE de recuperação automática - SIDRA. Disponível em: http://www.sidra.ibge. gov.br/. Acesso em: 15 dez. 2008.

INSTITUTO DE PESQUISA ECONÔMICA APLICADA - IPEA. Base de dados econômicos e sociais do Instituto de Pesquisa Econômica Aplicada - IPEADATA. Disponível em: http://www.ipeadata.gov.br/. Acesso em: 16 nov. 2008.

ISHII, K.S. Área monetária ótima para o Brasil: análise das diferenças regionais. 2008. 147 p. Tese (Doutorado em Economia Aplicada) - Escola Superior de Agricultura “Luiz de Queiroz", Universidade de São Paulo, Piracicaba, 2008.

JOHANSEN, S. Statistical analysis of cointegration vectors. Journal of Economics Dynamics and Control, Frankfurt, v. 12, 1988. p. 231-254.

JOHANSEN, S. Likelihood-based inference in cointegrated vector auto-regressive models. Oxford: Oxford University Press, 1995. p. 267.

LEAMER, E.; STERN, R. Quantitative international economics. Boston: Allyn and Bacon, 1970. p. 209.

LIMA, E.C.R. A interdependência entre os mercados de frangos e bovinos: uma aplicação da metodologia VAR-Estutural. Rio de Janeiro: Instituto de Pesquisa Econômica Aplicada - IPEA, jul. 1997. p .31. (Texto para discussão, 501).

LJUNG, G.M.; BOX, G.E.P. On a measurement of lack of fit in time series models. Biometrika, Oxford, v. 65, n. 2, 1978. p. 297-303.

MARGARIDO, M.A. Teste de co-integração de Johansen utilizando o SAS. Agricultura São Paulo, São Paulo, v. 51, n. 1, jan./jun. 2004. p. 87-101.

MIRANDA, S.H.G. de. Quantificação dos efeitos das barreiras não-tarifárias sobre as exportações brasileiras de carne bovina. 2001. 223 p. Tese (Doutorado em Economia Aplicada) - Escola Superior de Agricultura "Luiz de Queiroz", Universidade de São Paulo, Piracicaba, 2001.

OSAKI, M. Determinantes da oferta e da demanda por cebola argentina no Brasil nos anos 90. 2003. 101 p. Dissertação (Mestrado em Economia Aplicada) - Escola Superior de Agricultura "Luiz de Queiroz", Universidade de São Paulo, Piracicaba, 2003.

PAGLIETTINI, L.; GONZÁLEZ, C.C.; DOMÍNGUEZ, J. El complejo agroindustrial arrocero en Argentina: participación relativa de los agentes intervinientes. Revista Agroalimentaria, Caracas, n. 8. Jun. 1999. p. 81-90.

PORTUGAL, M.S. Um modelo de correção de erros por importações brasileira. Pesquisa e Planejamento Econômico, Rio de Janeiro, v. 22, n. 3, dez. 1992. p. 501-540. 
RESENDE, M.F.C. Disponibilidade cambial e especificação da função de demanda de importações para o Brasil. Brasília: Instituto de Pesquisa Econômica Aplicada IPEA, ago. 1997. p. 54. (Texto para discussão, 506).

RESENDE, M.F.C. Crescimento econômico, disponibilidade de divisas e importações no Brasil: um modelo de correção de erros. Pesquisa e Planejamento Econômico, Rio de Janeiro, v. 31, n. 2, ago. 2001. p. 289-330.

SANTOS, D.F. Políticas macroeconômicas e seus efeitos sobre as importações de lácteos no Brasil. 2004. 121 p. Tese (Doutorado em Economia Aplicada) - Escola Superior de Agricultura "Luiz de Queiroz", Universidade de São Paulo, Piracicaba, 2004.

SCARLATO, G. Gestión ambiental de los humedales de la Cuenca de la Laguna Marín 28: ordenamiento territorial y desarrollo sostenible: los problemas en el caso del arroz en Uruguay. Montevideo: CIEDUR, 2003. p. 34.

URUGUAI. Ministerio de Ganaderia, Agricultura y Pesca - MGAP, Direciones de Estadísticas Agropecuarias - DIEA. El cultivo de arroz em Uruguay: contribución a su conocimiento. Montevideo, 2004. 34 p. Disponível em: http://www.mgap. gub.uy/Diea/Rubros/Arroz/Arroz_Junio2003.pdf Acesso em: 28 set. 2008.

ZINI JUNIOR, A.A. Funções de exportação e de importação para o Brasil. Pesquisa e Planejamento Econômico, Rio de Janeiro, v. 18, n. 3, 1988. p. 615-662. 